\title{
Article
}

\section{Self-reported outcomes are associated with knee strength and functional symmetry in individuals who have undergone anterior cruciate ligament reconstruction with hamstring tendon autograft}

Harput, Gulcan, Ozer, Hamza, Baltaci, Gul and Richards, James Available at http://clok.uclan.ac.uk/23397/

Harput, Gulcan, Ozer, Hamza, Baltaci, Gul and Richards, James ORCID: 00000002-4004-3115 (2018) Self-reported outcomes are associated with knee strength and functional symmetry in individuals who have undergone anterior cruciate ligament reconstruction with hamstring tendon autograft. The Knee, 25 (5). pp. 757-764. ISSN 0968-0160

It is advisable to refer to the publisher's version if you intend to cite from the work. http://dx.doi.org/10.1016/j.knee.2018.06.007

For more information about UCLan's research in this area go to http://www.uclan.ac.uk/researchgroups/ and search for <name of research Group>.

For information about Research generally at UCLan please go to http://www.uclan.ac.uk/research/

All outputs in CLoK are protected by Intellectual Property Rights law, including Copyright law. Copyright, IPR and Moral Rights for the works on this site are retained by the individual authors and/or other copyright owners. Terms and conditions for use of this material are defined in the policies page. 
Self-reported outcomes are associated with knee strength and functional symmetry in individuals who have undergone $A C L$ reconstruction with hamstring tendon autograft

Gulcan Harput, PT, $\mathrm{PhD}^{1}$

Hamza Ozer, MD²

Gul Baltaci, PT, $\mathrm{PhD}^{3}$

Jim Richards, $\mathrm{PhD}^{4}$

${ }^{1}$ Hacettepe University, Faculty of Health Sciences, Department of Physiotherapy and Rehabilitation, Ankara, Turkey

${ }^{2}$ Gazi University, Faculty of Medicine, Department of Orthopaedic and Traumatology, Ankara, Turkey

${ }^{3}$ Private Ankara Guven Hospital, Ankara,Turkey

${ }^{4}$ University of Central Lancashire, Allied Health research Unit, Preston, United Kingdom

Correspond Author: Gulcan Harput

Address: Hacettepe University, Faculty of Health Sciences, Department of Physiotherapy and Rehabilitation, 06100, Samanpazari, Ankara, Turkey

Tel: 0903123051576

Fax: 0903123052012

e-mail: aktasgulcan@gmail.com , gulcan.aktas@hacettepe.edu.tr 


\section{ABSTRACT}

Background: The aim of this study was to investigate the relationship between selfreported knee outcomes and limb symmetry indices (LSIs) for hip and knee strength, postural control and single leg hop distance in individuals who had undergone an ACL reconstruction with hamstring tendon autograft (HTG).

Methods: A total of 72 participants with a history of unilateral ACL reconstruction with HTG (Mean \pm SD age, $28.0 \pm 7.6$ years; height, $178.4 \pm 6.7 \mathrm{~cm}$; mass, $76.9 \pm 14.9 \mathrm{~kg}$ ) were included. IKDC, Lysholm, KOOS and TAMPA scores were used to evaluate selfreported outcomes. Concentric and eccentric knee extensor and flexor strength, and hip abductor strength were measured with an isokinetic dynamometer. Postural control was assessed using the modified star excursion balance test and hop performance using the single leg hop test. The relationships between the LSI scores and the performance measures were explored using the Pearson correlation coefficient.

Results: The IKDC, Lysholm and KOOS scores were positively correlated with knee extensor and flexor strength LSIs $(p<0.05, r=0.34$ to $r=0.50)$, and the TAMPA score was negatively correlated with eccentric extensor LSI $(p=0.02, r=-0.34)$. Single leg hop distance LSI was correlated with IKDC and Lysholm scores $(p=0.003, r=0.50 ; p=0.04$, $r=0.29)$ respectively, while postural control was only correlated with the KOOS scores $(p<0.001, r=0.51$ to $r=0.52)$. No correlation was observed between self-reported outcomes and hip abductor strength ( $p>0.05)$.

Conclusions: Self-reported scores were correlated with knee extensor and flexor strength, postural control and hop performance in individuals who have undergone ACLR with HTG. Compared to Lysholm and TAMPA scores, KOOS and IKDC scores were more likely to be correlated with performance-based outcomes. Therefore, KOOS 
and IKDC scores may help clinicians in RTS decision making when there is a limited time to perform extensive evaluations or access equipment.

Key words: anterior cruciate ligament; patient-reported outcomes; muscle strength; star excursion balance test; hop performance; return to sport 


\section{Introduction}

Anterior cruciate ligament $(A C L)$ injuries mainly occur during sports which include cutting and pivoting maneuvers [1]. Individuals who suffer ACL injuries usually require $A C L$ reconstruction $(A C L R)$ if they wish to return to sport participation $[1,2]$. Allografts, bone-patellar tendon-bone and hamstring tendon autografts (HTG) are commonly used in ACLR [1,3-5]. However, the choice of HTG offers several advantages such as decreased postoperative pain, graft donor site morbidity, extension loss and postoperative quadriceps weakness [1, 3-5].

The most common criterion in return to sport (RTS) decision making after ACLR consists of strength and lower extremity functional performance testing with use of the limb symmetry index (LSI) and self-reported knee functions [6, 7]. Recently, patients have been allowed to return to a competitive level of sports when they achieve $90 \%$ on the LSI in quadriceps strength and hop performance tests [8, 9]. However the use of self-reported scores such as; the International Knee Documentation Committee 2000 Subjective Knee Form (IKDC), Knee Osteoarthritis Outcomes Scores (KOOS), Lysholm and TAMPA scores offer an important evaluation of the patients' quality of life, satisfaction, function, and kinesiophobia and may be related to objective measures of RTS [10-13]. Therefore, it is suggested that RTS decision should be made according to combination of subjective and objective measurements scores [10, 14].

The use of self-reported scores may help identify patients with neuromuscular impairments and activity limitations which may also be evaluated using isokinetic dynamometers and other performance-based test batteries when considering the return to sport phase of $A C L R$ rehabilitation $[10,11,15,16]$. Therefore, the use of simple questionnaires could help clinicians in the decision making of the patients ability 
to RTS when there is limited time to perform extensive evaluations or access to equipment such as isokinetic dynamometers [11]. However, there are conflicting findings in the literature documenting the relationship between subjective and objective measurement outcomes after ACLR. Extensor strength, postural control and hop performance have been shown to be related with subjective scores $[13,15,17]$, however some authors have failed to identify any relationship between objective outcomes and self-reported outcomes in individuals who had undergone ACLR [18, 19].

Such individuals may demonstrate different post-operative neuromuscular adaptations due to the graft used in the repair $[3,20]$, and may also provide information on the evaluation tools especially in self-reported functions. Therefore, the aim of this study was to investigate the relationship between self-reported knee outcomes including the IKDC, KOOS, Lysholm and TAMPA scores and limb symmetry indices for hip and knee strength, postural control and single leg hop distance in individuals who had undergone ACL reconstruction using a HTG. Hip abductor strength was also included as this may have a role in lower extremity alignment during functional activities [21] and has been previously identified as a possible risk factor for ACL injuries [22]. It was hypothesized that individuals with better self-reported knee scores would also have better limb symmetry indices and performance scores. 


\section{Materials and Methods}

\subsection{Participants}

Seventy-two male participants with a history of unilateral ACLR (age: $28.0 \pm 7.6$ years, height: $178.4 \pm 6.7 \mathrm{~cm}$, mass: $76.9 \pm 14.9 \mathrm{~kg}$, BMl: $24.2 \pm 4.2 \mathrm{~kg} / \mathrm{m}^{2}$, and preinjury Tegner activity score: $7.3 \pm 1.4$ ) were included in this study. Inclusion criteria were; age between 18 and 45 years, unilateral ACL reconstruction with hamstring tendon autograft, uninjured contralateral extremity, no history of neurological disease or vestibular or visual disturbance, and a pre-injury Tegner activity score of at least 5. Participants were excluded if they had an ACL revision, ACLR with patellar tendon autograft or allograft, posterior cruciate ligament injury and/or reconstruction, or had a previous injury or surgery to the contralateral limb. All patients were operated by the same surgeon $(\mathrm{HO})$ with single-bundle anatomic ACLR using 4-strand semitendinosus and gracilis tendon autograft, and went through the same rehabilitation program after the ACLR. All patients were requested not to return to sport specific training program before the end of 6 months after surgery. Written informed consent was obtained from all participants, and the study was approved by the University Institutional Review Board.

\subsection{ACLR rehabilitation}

ACLR rehabilitation program started within the first week of surgery and the patients were instructed to visit physical therapy 3 days a week till week 12 after ACLR. The early rehabilitation program (0-4 weeks) emphasized limiting hemarthrosis and edema, obtaining full knee range of motion, achieving good quadriceps muscle control and normalization of the walking. Then, the rehabilitation program (4-12 weeks) included progressive neuromuscular training including core, balance and 
strengthening exercises mostly performed on weight-bearing positions. The rehabilitation program until 12 weeks after surgery did not include any open kinetic chain quadriceps exercises for the reconstructed and the healthy limbs.

From 12th week to 24th week, all participants were instructed to perform the same training program. This program includes resistive hip and knee strengthening, plyometric, running and balance exercises for both limbs 3 days in a week during this period.

\subsection{Data collection}

Data collection was performed six months post-surgery in a single testing session, as the RTS tests are frequently perform at this time point.

\subsubsection{Postural control}

Modified Star Excursion Balance Test (SEBT) with anterior (ANT), posteromedial $(P M)$ and posterolateral $(P L)$ reach directions was used to evaluate the postural control of the participants [23]. This test has been shown to be a reliable tool to determine the balance deficits between limbs in individuals who had lower extremity injuries $[23,24]$. Participants were instructed to stand in the middle of a grid with tapelines extending out 100 centimeters in the three directions. The angle between ANT and PM or PL lines was set at $135^{\circ}$ and the angle between PM and PL lines was set at $90^{\circ}$. Participants were instructed to reach as far as possible along each of the 3 lines, make a light toe-touch on the line without shifting weight, and return to the center of the grid whilst maintaining single-leg balance. Three practice trials were given for each limb for each direction. Participants then performed 3 trials in the 3 directions. Measurements were taken from the most distal aspect of the toes, and the average of the 3 reach distances in each direction was calculated for each limb. The reach 
distance of the involved limb was divided by the reach distance of the uninvolved limb and expressed as a percentage.

\subsubsection{Hop distance}

Single leg hop test (SLHT) was used to assess the hop performance of the participants. The participants stood on single leg with toes behind a mark on the floor. They were instructed to jump as far as possible with a controlled landing. The test was performed until three successful jumps were performed for each leg. The distance was measured in centimeters and the average of the three trials was recorded. The tests were performed with the uninvolved limb first followed by the involved limb. The hop distance of the involved limb was divided by the hop distance of the uninvolved limb and expressed as a percentage.

\subsubsection{Knee and hip strength}

An isokinetic dynamometer (IsoMed $® 2000$ D\&R GmbH, Germany) was used to measure the concentric and eccentric knee extensor and flexor, and hip abductor strength at an angular velocity of $90 \%$ s.

The concentric and eccentric knee extension/flexion strength measurements were performed with the participants seated on the dynamometer with the hip and knee joints flexed to $90^{\circ}$. Stabilization straps were placed across the trunk, waist and the distal femur of the limb to minimize compensatory movement. The axis of the dynamometer was aligned to the lateral femoral epicondyle while the knee was flexed at $90^{\circ}$ and the dynamometer force arm was secured $2 \mathrm{~cm}$ above the lateral malleolus. Prior to strength recordings, the participants were allowed three maximal concentric and eccentric quadriceps and hamstring tests to familiarize themselves with the testing procedures and to warm-up. The participants then performed five reciprocal maximal 
concentric and eccentric extension/flexion contractions through a ROM of $90^{\circ}$ with a two minute rest interval between each set.

For hip abductor strength measurement, participants were positioned in side lying with the knee of the side to be tested fully extended and the contralateral knee flexed to $90^{\circ}$. Two stabilization straps were placed over the anterior superior iliac spine and contralateral knee to prevent compensatory movements. The axis of the dynamometer was aligned to the greater trochanter of tested limb. The dynamometer lever arm was secured superior to the lateral knee joint line and the ROM was set to $45^{\circ}$ of hip abduction. The participants then performed 5 reciprocal concentric and eccentric hip abduction contractions.

The knee strength measurements were performed prior to the hip strength test and the order of the muscles tested was randomized to minimize the effect of fatigue on individual muscular performance. Standardized verbal instructions were given for each test procedure. Normalized peak torque $(\mathrm{Nm} / \mathrm{kg})$ values for involved and uninvolved limbs were recorded. The muscle strength indices were calculated by the torque produced by the involved limb divided by the torque produced by the uninvolved limb, which were then expressed as percentages.

\subsubsection{Self-reported outcomes}

The knee injury and osteoarthritis outcomes (KOOS) score was used to evaluate subjective knee function. This has five subscales evaluating symptoms, pain, function in daily life (DL), and function during sport and recreational activity (Sport/Rec) and knee-related quality of life (QoL). Each subscale was scored from 0 to 100, where a score of 100 indicates good knee function [25, 26]. 
The Lysholm score was used to evaluate patients' knee function following knee ligament injury. This comprises of an eight-item questionnaire with a maximum score of 100 points, indicating no symptoms [27, 28].

The International knee documentation committee (IKDC) subjective knee form was used to measure symptoms, function and sports activity. This has previously been used to assess people with knee disorders, including ligamentous and meniscal injuries, osteoarthritis and patellofemoral dysfunction. This form contains 18 selected items designed to measure symptoms which allows clinicians to assess pain, stiffness, swelling, joint locking and joint instability, while other items designed to measure knee function evaluate the ability to perform activities associated with daily living. The total IKDC is scored from 0 to 100 , with 100 indicating the absence of symptoms and higher levels of knee function [29, 30].

The Tampa scale of kinesiophobia (TSK) was used to assess the fear of reinjury, movement and physical activity. The TSK has previously been associated with not returning to sports after ACL injury [31]. Results for the total score range from 1768, the higher the score indicating an increasing degree of kinesiophobia [32].

\subsubsection{Statistical analysis}

SPSS 22.0 (SPSS Inc, Chicago, IL) was used for statistical analysis. Data were expressed as means and standard deviations (SD) for descriptive data. A Kolmogorov Smirnov test was performed to test the normal distribution of the data, and all data were found suitable for parametric testing. Pearson product moment coefficient correlation tests were used to analyze the relationship between self-reported scores and performance-based outcomes. Each correlation coefficient $(r)$ was interpreted based on a previously described classification using similar variables: 0 to 0.4 (weak), 
0.4 to 0.7 (moderate), and 0.7 to 1.0 (strong) [33]. Student t test were also performed to determine the difference between involved and uninvolved limb for the performancebased outcomes. Statistical significance level was set at $p<0.05$.

\section{Results}

Descriptive statistics for self-reported and performance-based outcomes are reported in Table 1-3. The knee extensor and flexor strength, SLHT outcomes were significantly lower in involved limb compared to uninvolved limb $(p<0.001)$. SEBT outcomes and hip abductor strength were found to be similar between limbs ( $p>0.05)$. (Table 2-3).

Significant moderate positive correlations were seen between IKDC score and LSIs for concentric $(p<0.001, r=0.45)$, eccentric knee extensor $(p=0.009, r=0.39)$, eccentric knee flexor $(p<0.001, r=0.47)$, and SLHT $(p=0.003, r=0.50)$. The Lysholm score showed significant but weak positive correlations with concentric $(p=0.03$, $r=0.30)$, eccentric knee extensor strength $(p=0.02, r=0.34)$ and SLHT LSIs $(p=0.04$, $r=0.29)$.

Moderate positive correlations were observed between concentric flexor strength and KOOS "symptoms" $(p<0.001, r=0.53)$ and "pain" subscores $(p=0.02$, $r=0.32$ ). In addition, eccentric knee flexor strength showed moderate positive correlations with KOOS "symptoms" $(p=0.01, r=0.35)$ and "pain" subscores $(p=0.001$, $r=0.47)$. KOOS "Sport/Rec" was positively correlated with SLHT ( $p=0.04, r=0.30)$, SEBT_ANT $(p<0.001, r=0.52)$ and SEBT_PL_LSIs $(p<0.001, r=0.51)$. In addition, KOOS "Sport/Rec" was positively correlated with concentric $(p=0.02, r=0.53)$, eccentric knee flexor strength LSIs $(p=0.001, r=0.47)$ and concentric knee extensor strength $L S I$ $(p=0.03, r=0.31)$. KOOS "QoL" was correlated with SLHT $(p=0.002, r=0.45)$, concentric 
and eccentric knee flexor strength LSIs $(p=0.002, r=0.45 ; p=0.004, r=0.43)$ respectively, and concentric and eccentric knee extensor strength LSIs $(p=0.001$, $r=0.47 ; p=0.004, r=0.44$ ) respectively.

The Tampa score showed a weak negative correlation with eccentric quadriceps LSIs $(p=0.02, r=-0.34)$. No correlation was seen between self-reported knee scores and hip abductor strength LSIs ( $p>0.05)$.

Table 1. Descriptive statistics of the self-reported outcomes.

\begin{tabular}{|l|l|}
\hline Self-reported outcomes & Mean \pm SD \\
\hline IKDC & $81.2 \pm 11.5$ \\
\hline LYSHOLM & $96.6 \pm 3.9$ \\
\hline KOOS & \\
Symptoms & $84.8 \pm 10.7$ \\
Pain & $89.0 \pm 8.1$ \\
Function in daily life & $97.1 \pm 2.9$ \\
Function during Sport/Rec & $81.6 \pm 15.9$ \\
Knee related quality of life & $74.7 \pm 14.5$ \\
\hline TAMPA & $37.8 \pm 5.9$ \\
\hline
\end{tabular}

Abbreviations: IKDC, International knee documentation committee; KOOS, knee injury and osteoarthritis outcomes score

Table 2. Descriptive statistics of the knee extensor and flexor, and hip abduction isokinetic strength for involved and uninvolved limbs.

\begin{tabular}{|c|c|c|c|c|c|}
\hline Strength & $\begin{array}{l}\text { Involved limb } \\
\text { (Nm/kg) }\end{array}$ & $\begin{array}{l}\text { Uninvolved } \\
\text { Limb (Nm/kg) }\end{array}$ & $\begin{array}{l}95 \% \mathrm{Cl} \text { of the } \\
\text { difference }\end{array}$ & P value & $\begin{array}{l}\text { Limb } \\
\text { symmetry } \\
\text { index (\%) }\end{array}$ \\
\hline $\begin{array}{c}\text { Knee extensor } \\
\text { Concentric } \\
\text { Eccentric }\end{array}$ & $\begin{array}{l}2.71 \pm 0.99 \\
2.95 \pm 1.05\end{array}$ & $\begin{array}{l}3.04 \pm 0.74 \\
3.56 \pm 0.79\end{array}$ & $\begin{array}{l}-0.49,-0.15 \\
-0.76,-0.46\end{array}$ & $\begin{array}{l}<0.001 \\
<0.001\end{array}$ & $\begin{array}{l}89.8 \pm 22.2 \\
82.1 \pm 19.8\end{array}$ \\
\hline $\begin{array}{c}\text { Knee flexor } \\
\text { Concentric } \\
\text { Eccentric }\end{array}$ & $\begin{array}{l}1.91 \pm 0.36 \\
2.14 \pm 0.39\end{array}$ & $\begin{array}{l}2.03 \pm 0.39 \\
2.45 \pm 0.44\end{array}$ & $\begin{array}{l}-0.19,-0.04 \\
-0.37,-0.25\end{array}$ & $\begin{array}{l}<0.001 \\
<0.001\end{array}$ & $\begin{array}{l}95.3 \pm 14.6 \\
87.8 \pm 9.5\end{array}$ \\
\hline $\begin{array}{c}\text { Hip abductor } \\
\text { Concentric } \\
\text { Eccentric }\end{array}$ & $\begin{array}{l}1.56 \pm 0.36 \\
1.83 \pm 0.49\end{array}$ & $\begin{array}{l}1.52 \pm 0.38 \\
1.80 \pm 0.43\end{array}$ & $\begin{array}{l}-0.02,0.11 \\
-0.05,0.10 \\
\end{array}$ & $\begin{array}{l}0.47 \\
0.22\end{array}$ & $\begin{array}{l}104.9 \pm 19.7 \\
102.2 \pm 16.9\end{array}$ \\
\hline
\end{tabular}

Abbreviations: $\mathrm{Cl}$, confidence interval 
Table 3. Descriptive statistics of the hop performance and postural control outcomes for involved and uninvolved limbs.

\begin{tabular}{|l|l|l|l|l|l|}
\hline $\begin{array}{l}\text { Functional } \\
\text { tests }\end{array}$ & $\begin{array}{l}\text { Involved } \\
\text { limb (cm) }\end{array}$ & $\begin{array}{l}\text { Uninvolved } \\
\text { Limb (cm) }\end{array}$ & $\begin{array}{l}\text { 95\% Cl of the } \\
\text { difference }\end{array}$ & $\begin{array}{l}\mathbf{P} \\
\text { value }\end{array}$ & $\begin{array}{l}\text { Limb } \\
\text { symmetry } \\
\text { index (\%) }\end{array}$ \\
\hline SLHT & $149.53 \pm 29.60$ & $163.32 \pm 26.25$ & $-20.58,-7.01$ & $<0.001$ & $90.0 \pm 12.6$ \\
\hline $\begin{array}{l}\text { SEBT } \\
\text { Anterior }\end{array}$ & $69.86 \pm 6.41$ & $70.67 \pm 5.72$ & $-1.70,0.06$ & 0.07 & $98.9 \pm 4.9$ \\
Posteromedial & $88.72 \pm 10.38$ & $89.74 \pm 10.78$ & $-2.30,0.28$ & 0.12 & $99.1 \pm 5.6$ \\
Posterolateral & $87.84 \pm 13.96$ & $89.12 \pm 13.34$ & $-2.84,0.27$ & 0.10 & $98.7 \pm 6.4$ \\
\hline
\end{tabular}

Abbreviations: SLHT, single leg hop test; SEBT, star excursion balance test; $\mathrm{Cl}$, confidence interval

Table 4. Correlation between self-reported and performance based outcomes. SAMPLE (needs $p$ values, too hard to write down all the numbers.)

\begin{tabular}{|c|c|c|c|c|c|c|c|c|c|}
\hline & & \multirow{2}{*}{ IKDC } & \multirow{2}{*}{ Lysholm } & \multicolumn{5}{|c|}{ KOOS } & \multirow{2}{*}{ TAMPA } \\
\hline & & & & Symp & Pain & $\mathrm{DL}$ & Sport & QoL & \\
\hline Knee extensor & $\begin{array}{l}\text { Con } \\
\text { Ecc }\end{array}$ & $\begin{array}{l}r=0.45 \\
r=0.39\end{array}$ & $\begin{array}{l}r=0.30 \\
r=0.34\end{array}$ & $\begin{array}{l}\text { NS } \\
\text { NS }\end{array}$ & $\begin{array}{l}\text { NS } \\
\text { NS }\end{array}$ & $\begin{array}{l}\text { NS } \\
\text { NS }\end{array}$ & $\begin{array}{l}r=0.31 \\
N S\end{array}$ & $\begin{array}{l}r=0.47 \\
r=0.44\end{array}$ & $\begin{array}{l}\text { NS } \\
r=-0.34\end{array}$ \\
\hline Knee flexor & $\begin{array}{l}\text { Con } \\
\text { Ecc }\end{array}$ & $\begin{array}{l}\text { NS } \\
r=0.47\end{array}$ & $\begin{array}{l}\text { NS } \\
\text { NS }\end{array}$ & $\begin{array}{l}r=0.53 \\
r=0.35\end{array}$ & $\begin{array}{l}r=0.32 \\
r=0.47\end{array}$ & $\begin{array}{l}\text { NS } \\
\text { NS }\end{array}$ & $\begin{array}{l}r=0.53 \\
r=0.47\end{array}$ & $\begin{array}{l}r=0.45 \\
r=0.43\end{array}$ & $\begin{array}{l}\text { NS } \\
\text { NS }\end{array}$ \\
\hline Hip abductor & $\begin{array}{l}\text { Con } \\
\text { Ecc }\end{array}$ & $\begin{array}{l}\text { NS } \\
\text { NS }\end{array}$ & $\begin{array}{l}\text { NS } \\
\text { NS }\end{array}$ & $\begin{array}{l}\text { NS } \\
\text { NS }\end{array}$ & $\begin{array}{l}\text { NS } \\
\text { NS }\end{array}$ & $\begin{array}{l}\text { NS } \\
\text { NS }\end{array}$ & $\begin{array}{l}\text { NS } \\
\text { NS }\end{array}$ & $\begin{array}{l}\text { NS } \\
\text { NS }\end{array}$ & $\begin{array}{l}\text { NS } \\
\text { NS }\end{array}$ \\
\hline SEBT & $\begin{array}{l}\text { Ant } \\
\text { Pm } \\
\text { PI }\end{array}$ & $\begin{array}{l}\text { NS } \\
\text { NS } \\
\text { NS }\end{array}$ & $\begin{array}{l}\text { NS } \\
\text { NS } \\
\text { NS }\end{array}$ & $\begin{array}{l}\text { NS } \\
\text { NS } \\
\text { NS }\end{array}$ & $\begin{array}{l}\text { NS } \\
\text { NS } \\
\text { NS }\end{array}$ & $\begin{array}{l}\text { NS } \\
\text { NS } \\
\text { NS }\end{array}$ & $\begin{array}{l}r=0.52 \\
N S \\
r=0.51\end{array}$ & $\begin{array}{l}\text { NS } \\
\text { NS } \\
\text { NS }\end{array}$ & $\begin{array}{l}\text { NS } \\
\text { NS } \\
\text { NS }\end{array}$ \\
\hline SLHT & & $r=0.50$ & $r=0.29$ & NS & NS & NS & $r=0.30$ & $r=0.45$ & NS \\
\hline
\end{tabular}

Abbreviations, International Knee Documentation Committee (IKDC), Knee Injury and Osteoarthritis Outcome Score (KOOS)

$r=$ correlation coefficient (significant $\mathrm{p}<0.05$ ), NS - not significant

\section{Discussion}

This study showed that self-reported outcomes assessed using IKDC, KOOS, Lysholm and TAMPA scores in individuals who had undergone ACLR with HTG at 6 months post-surgery were related to knee extensor and flexor strength, postural control and hop performance LSIs with a low to moderate correlation. Whereas, hip abductor strength LSI was not correlated with any of patient reported outcomes. Therefore, patient's perspective for their knee function and level of kinesiophobia might be associated with their knee strength and performance at the return to sport phase of $A C L$ rehabilitation. 
Knee specific self-reported outcomes reflect the patient's perspective on how the knee injury affects their daily life including symptoms, function, quality of life and activity level. IKDC score is the most widely used patient reported outcome to evaluate subjective knee functions in individuals who had ACL injuries and/or surgery. In this study, the mean IKDC score of the participants was 81 which shows a $19 \%$ deficit, which is lower than the normative values for healthy individuals for a similar age range [34]. IKDC score was found to be related to LSIs for concentric and eccentric knee extensor and flexor strength and related to single leg hop distance, but the correlations were only moderate. Our findings are consistent with previous findings, which have shown positive weak to strong associations between IKDC score and knee extensor strength in individuals who had undergone ACLR [14, 35, 36]. Zwolski et al.[14] suggested that score of $>94.8$ on the IKDC is likely to indicate that a patient's quadriceps strength is at an acceptable level for RTS. Individuals whose IKDC score was below the normal range were more than 4.5 times more likely to have failed RTS at 6 months post ACLR [11]. To our knowledge, this is the first study to investigate the association between IKDC score and hamstring strength in individuals who had undergone ACLR with HTG. We found that moderate correlations exist between IKDC score and LSIs for hamstring eccentric and concentric strength. This important finding indicates that IKDC score could reflect the hamstring strength impairments after ACLR with HTG at 6 months after surgery.

Although the sensitivity of the Lysholm score for detecting functional deficits in patients with ACL surgery is questionable when compared to other self-reported knee function scores, it is still frequently used for evaluating subjective knee outcomes. In this study, the mean Lysholm score was 96 which is accepted as a normal value, this was found to be only related with concentric and eccentric knee extensor strength LSIs, 
and hop performance with weak correlations. Contrary to our findings, Dobija et al.[37] found positive correlation between Lysholm score and SEBT PM reach direction in individuals with ACL deficiency with moderate correlation.

In this present study, lower scores for KOOS were observed in "symptoms", "Sport/Rec" and "QoL" subscores. Postural control evaluated with the modified SEBT was correlated only with KOOS "Sport/Rec". Consistent with our findings, Trulsson et al.[38] also showed that altered postural orientation was related with worse KOOS "sport and recreation". KOOS "symptoms and pain" subscores were only related to knee flexor strength LSI, whereas KOOS "Sport/Rec" and "quality of life" subscores were correlated with both knee extensor and flexor strength LSIs. Hence, it could be said that KOOS score is more related with knee flexor strength and postural control LSIs in individuals who had undergone ACLR with HTG. This is in agreement with Holsgaard-Larsen et al.[39] who found moderate to strong correlations between KOOS "sport" and "quality of life" subscales and knee extensor and flexors strength in patients with ACL surgery. They suggested that improving quadriceps and hamstring strength might improve the quality of life and function in sport.

The Tampa score has been widely used for assessing the fear of re-injury in individuals during the return to sport phase after ACL surgery $[11,40,41]$. Although TSK scores generally decrease after ACL surgery, higher TSK scores still exist in after rehabilitation post ACLR and has been associated with the lower knee function.[11, 40] The mean TSK score of the participants in this study was 35 and which showed a low to moderate correlation with eccentric quadriceps LSIs. This is contrary to the findings by Lentz et al.[41], who did not find a significant correlation between TSK score and quadriceps eccentric LSI. Although correlation between knee strength and TSK 
score was weak in this current study, we suggest that eccentric quadriceps strength deficit may affect the kinesiophobia level in individuals who have undergone ACLR.

We are not aware of any study that investigated the associations between hip strength and self-reported outcomes in ACLR individuals, therefore we could not compare our results to previous findings. The reason for the consideration on hip abductor muscles' strength was to their role in stabilizing the pelvis during single leg activities. In addition, deficits in hip abductor strength have been shown related with second $A C L$ injury risk following $A C L R[21,22]$. Contrary to our expectation, no correlations were observed between hip abductor strength LSIs and the self-reported knee outcomes. Unlike knee extensor and flexor strength, hip abductor strength may not directly affect patients' perception of their knee function.

The literature suggests that 6 months after ACLR is a critical time point when RTS decisions are frequently made. Although the RTS criteria that clinicians use to make this determination are highly variable, RTS decision is usually made up several performance-based tests including; muscle strength, postural control and hop performance $[1,8,9]$. Limb symmetry indices for strength and performance are also a common method to evaluate the difference between involved and uninvolved limbs. Recent studies suggest $90 \%$ or $100 \%$ LSI for knee strength and performance is needed before a return to sports is advised, which includes pivoting and cutting activities $[1,8$, $9,42]$. The strength deficits after ACLR have been shown to be graft-specific and knee extensor strength deficits are observed more in patients with BPTB and knee flexor strength deficit are present in patients with HTG [20]. In present study, knee flexor strength LSI was found 95\% for concentric and 88\% for eccentric strength while knee extensor strength LSI was $90 \%$ for concentric and $82 \%$ for eccentric contractions. Therefore, the participants of the study had not completely reached the desired level 
for knee extensor and flexor strength criteria of RTS at 6 months post-surgery. It was documented that deficits in quadriceps strength may persist for up to 2 years following ACLR [43] and quadriceps strength deficit of more than $15 \%$, causes asymmetries during squatting, landing and jumping activities [42, 44]. Gokeler et al. [45] also suggested that recovery of quadriceps strength might not be complete within the first year after ACLR. This is supported from our findings that eccentric strength deficits were greater than concentric strength deficits for both knee extensor and flexor muscles at 6 months after ACLR. Therefore, we recommended that eccentric strength measurements should be included in evaluation program after ACLR especially in RTS period. However, we did not observe strength deficit in concentric and eccentric contractions of hip abductor muscles.

The LSIs for modified SEBT and SLHT reached greater than 90\%. Both SEBT and SLHT are the performance-based knee function tests that are commonly used to assess the neuromuscular control deficits of the individuals who had ACL injuries/surgery especially in RTS decision. SLHT is also frequently used for evaluating confidence in the injured limb and to ability to tolerate the loads in landing after jump $[8,9,23,42,46]$

\subsection{Limitations}

To include a homogenous sample, the present patient group was composed by male patients who had ACLR with HTG. Ageberg et al. [47] reported that sex difference could exist in self-reported knee function after ACLR. Hence, the results of this study do not address any potential gender or graft difference in these factors, which may reduce the generalizability of the present findings. Due to cross-sectional design of the study, the results only demonstrate the association between subjective and objective 
outcomes at 6 months after ACLR so the findings of the study is not able to reflect the long term after surgery.

\section{Conclusions}

Self-reported outcomes assessed with IKDC, KOOS, Lysholm and TAMPA scores were related with knee extensor and flexor strength, postural control and hop performance symmetry in individuals who had undergone ACLR with HTG at the time when return to sport is frequently considered. Hip abductor strength was not correlated with any of patient reported outcomes. These associations suggest that improving knee strength and knee function during ACL rehabilitation could improve patient's perspective on their knee function. Compared to Lysholm and TAMPA scores, KOOS and IKDC scores had a greater correlation with performance-based outcomes, which may help clinicians in RTS decision making when there is a limited time to perform extensive evaluations or access equipment. 


\section{References}

[1] Ageberg E, Roos HP, Silbernagel KG, Thomee R, Roos EM. Knee extension and flexion muscle power after anterior cruciate ligament reconstruction with patellar tendon graft or hamstring tendons graft: a cross-sectional comparison 3 years post surgery. Knee Surg Sports Traumatol Arthrosc. 2009;17: 162-9.

[2] Beynnon BD, Johnson RJ, Abate JA, Fleming BC, Nichols CE. Treatment of anterior cruciate ligament injuries, part I. Am J Sports Med. 2005;33: 1579-602.

[3] Eriksson K, Anderberg P, Hamberg P, Olerud P, Wredmark T. There are differences in early morbidity after $A C L$ reconstruction when comparing patellar tendon and semitendinosus tendon graft. A prospective randomized study of 107 patients. Scand J Med Sci Sports. 2001;11: 170-7.

[4] Kim HS, Seon JK, Jo AR. Current trends in anterior cruciate ligament reconstruction. Knee Surg Relat Res. 2013;25: 165-73.

[5] West RV, Harner CD. Graft selection in anterior cruciate ligament reconstruction. J Am Acad Orthop Surg. 2005;13: 197-207.

[6] Fitzgerald GK, Axe MJ, Snyder-Mackler L. A decision-making scheme for returning patients to high-level activity with nonoperative treatment after anterior cruciate ligament rupture. Knee Surg Sports Traumatol Arthrosc. 2000;8: 76-82.

[7] Hopper DM, Goh SC, Wentworth LA, Chan DYK, Chau JHW, Wootton GJ, et al. Test-retest reliability of knee rating scales and functional hop tests one year following anterior cruciate ligament reconstruction. Physical Therapy in Sport. 2002;3: 10-18.

[8] Adams D, Logerstedt DS, Hunter-Giordano A, Axe MJ, Snyder-Mackler L. Current concepts for anterior cruciate ligament reconstruction: a criterion-based rehabilitation progression. J Orthop Sports Phys Ther. 2012;42: 601-14.

[9] Lynch AD, Logerstedt DS, Grindem H, Eitzen I, Hicks GE, Axe MJ, et al. Consensus criteria for defining 'successful outcome' after ACL injury and reconstruction: a Delaware-Oslo ACL cohort investigation. $\mathrm{Br} \mathrm{J}$ Sports Med. 2015;49: 335-42.

[10] Bjorklund K, Andersson L, Dalen N. Validity and responsiveness of the test of athletes with knee injuries: the new criterion based functional performance test instrument. Knee Surg Sports Traumatol Arthrosc. 2009;17: 435-45.

[11] Logerstedt D, Di Stasi S, Grindem H, Lynch A, Eitzen I, Engebretsen L, et al. Self-reported knee function can identify athletes who fail return-to-activity criteria up to 1 year after anterior cruciate ligament reconstruction: a delawareoslo ACL cohort study. J Orthop Sports Phys Ther. 2014;44: 914-23.

[12] Nyland J, Cottrell B, Harreld K, Caborn DN. Self-reported outcomes after anterior cruciate ligament reconstruction: an internal health locus of control score comparison. Arthroscopy. 2006;22: 1225-32.

[13] Wilk KE, Romaniello WT, Soscia SM, Arrigo CA, Andrews JR. The Relationship between Subjective Knee Scores, Isokinetic Testing, and Functional Testing in the Acl-Reconstructed Knee. J Orthop Sport Phys. 1994;20: 60-73.

[14] Zwolski C, Schmitt LC, Quatman-Yates C, Thomas S, Hewett TE, Paterno MV. The influence of quadriceps strength asymmetry on patient-reported function at time of return to sport after anterior cruciate ligament reconstruction. Am J Sports Med. 2015;43: 2242-9.

[15] Granan LP, Baste V, Engebretsen L, Inacio MC. Associations between inadequate knee function detected by KOOS and prospective graft failure in an 
anterior cruciate ligament-reconstructed knee. Knee Surg Sports Traumatol Arthrosc. 2015;23: 1135-40.

[16] Harreld K, Nyland J, Cottrell B, Caborn DN. Self-reported patient outcomes after ACL reconstruction with allograft tissue. Med Sci Sports Exerc. 2006;38: 205867.

[17] Park WH, Kim DK, Yoo JC, Lee YS, Hwang JH, Chang MJ, et al. Correlation between dynamic postural stability and muscle strength, anterior instability, and knee scale in anterior cruciate ligament deficient knees. Arch Orthop Traum Su. 2010;130: 1013-18.

[18] Moller E, Weidenhielm L, Werner S. Outcome and knee-related quality of life after anterior cruciate ligament reconstruction: a long-term follow-up. Knee Surg Sports Traumatol Arthrosc. 2009;17: 786-94.

[19] Hyder N, Bollen S, Sefton G, Swann A. Correlation between arthrometric evaluation of knees using KT 1000 and Telos stress radiography and functional outcome following ACL reconstruction. The Knee. 1997;4: 121-24.

[20] Xergia SA, McClelland JA, Kvist J, Vasiliadis HS, Georgoulis AD. The influence of graft choice on isokinetic muscle strength 4-24 months after anterior cruciate ligament reconstruction. Knee Surg Sports Traumatol Arthrosc. 2011;19: 76880.

[21] Sugimoto D, Mattacola CG, Mullineaux DR, Palmer TG, Hewett TE. Comparison of Isokinetic Hip Abduction and Adduction Peak Torques and Ratio Between Sexes. Clin J Sport Med. 2014;24: 422-28.

[22] Hollman JH, Ginos BE, Kozuchowski J, Vaughn AS, Krause DA, Youdas JW. Relationships Between Knee Valgus, Hip-Muscle Strength, and Hip-Muscle Recruitment During a Single-Limb Step-Down. J Sport Rehabil. 2009;18: 10417.

[23] Gribble PA, Hertel J, Plisky P. Using the Star Excursion Balance Test to assess dynamic postural-control deficits and outcomes in lower extremity injury: a literature and systematic review. J Athl Train. 2012;47: 339-57.

[24] Munro AG, Herrington LC. Between-session reliability of the star excursion balance test. Phys Ther Sport. 2010;11: 128-32.

[25] Paker NB, D.; Sabirli, F.; Ozel, S.; Ersoy, S. Knee Injury and Osteoarthritis Outcome Score: reliability and validation of the Turkish version. Turkiye Klinikleri J Med Sci. 2007;27: 350-56.

[26] Roos EM, Roos HP, Lohmander LS, Ekdahl C, Beynnon BD. Knee Injury and Osteoarthritis Outcome Score (KOOS)--development of a self-administered outcome measure. J Orthop Sports Phys Ther. 1998;28: 88-96.

[27] Celik D, Coskunsu D, Kilicoglu O. Translation and cultural adaptation of the Turkish Lysholm knee scale: ease of use, validity, and reliability. Clin Orthop Relat Res. 2013;471: 2602-10.

[28] Lysholm J, Gillquist J. Evaluation of knee ligament surgery results with special emphasis on use of a scoring scale. Am J Sports Med. 1982;10: 150-4.

[29] Celik D, Coskunsu D, KiliCoglu O, Ergonul O, Irrgang JJ. Translation and crosscultural adaptation of the international knee documentation committee subjective knee form into Turkish. J Orthop Sports Phys Ther. 2014;44: 899909.

[30] Irrgang JJ, Anderson AF, Boland AL, Harner CD, Kurosaka M, Neyret P, et al. Development and validation of the international knee documentation committee subjective knee form. Am J Sports Med. 2001;29: 600-13. 
[31] Kvist J, Ek A, Sporrstedt K, Good L. Fear of re-injury: a hindrance for returning to sports after anterior cruciate ligament reconstruction. Knee Surg Sports Traumatol Arthrosc. 2005;13: 393-7.

[32] Kori S, Miller R, Todd D. Kinesiophobia: a new view of chronic pain behavior. Pain management. 1990;3: 35-43.

[33] Cohen J. Statistical power analysis. Current directions in psychological science. 1992;1: 98-101.

[34] Anderson AF, Irrgang JJ, Kocher MS, Mann BJ, Harrast JJ, International Knee Documentation $C$. The International Knee Documentation Committee Subjective Knee Evaluation Form: normative data. Am J Sports Med. 2006;34: 128-35.

[35] Goetschius J, Hart JM. Knee-Extension Torque Variability and Subjective Knee Function in Patients with a History of Anterior Cruciate Ligament Reconstruction. J Athl Train. 2016;51: 22-7.

[36] Pietrosimone BG, Lepley AS, Ericksen HM, Gribble PA, Levine J. Quadriceps strength and corticospinal excitability as predictors of disability after anterior cruciate ligament reconstruction. J Sport Rehabil. 2013;22: 1-6.

[37] Dobija L, Coudeyre E, Pereira B. Measurement properties of the Star Excursion Balance Test in the anterior crucial ligament-deficient subjects - preliminary analysis. Ann Phys Rehabil Med. 2016;59S: e18.

[38] Trulsson A, Roos EM, Ageberg E, Garwicz M. Relationships between postural orientation and self reported function, hop performance and muscle power in subjects with anterior cruciate ligament injury. BMC musculoskeletal disorders. 2010;11: 143.

[39] Holsgaard-Larsen A, Jensen C, Aagaard P. Subjective vs objective predictors of functional knee joint performance in anterior cruciate ligament-reconstructed patients--do we need both? Knee. 2014;21: 1139-44.

[40] Hartigan EH, Lynch AD, Logerstedt DS, Chmielewski TL, Snyder-Mackler L. Kinesiophobia after anterior cruciate ligament rupture and reconstruction: noncopers versus potential copers. J Orthop Sports Phys Ther. 2013;43: 82132.

[41] Lentz TA, Tillman SM, Indelicato PA, Moser MW, George SZ, Chmielewski TL. Factors associated with function after anterior cruciate ligament reconstruction. Sports Health. 2009;1: 47-53.

[42] Schmitt LC, Paterno MV, Hewett TE. The impact of quadriceps femoris strength asymmetry on functional performance at return to sport following anterior cruciate ligament reconstruction. J Orthop Sports Phys Ther. 2012;42: 750-9.

[43] Risberg MA, Holm I, Tjomsland O, Ljunggren E, Ekeland A. Prospective study of changes in impairments and disabilities after anterior cruciate ligament reconstruction. J Orthop Sports Phys Ther. 1999;29: 400-12.

[44] Ernst GP, Saliba E, Diduch DR, Hurwitz SR, Ball DW. Lower extremity compensations following anterior cruciate ligament reconstruction. Phys Ther. 2000;80: 251-60.

[45] Gokeler A, Bisschop M, Benjaminse A, Myer GD, Eppinga P, Otten E. Quadriceps function following $A C L$ reconstruction and rehabilitation: implications for optimisation of current practices. Knee Surg Sports Traumatol Arthrosc. 2014;22: 1163-74.

[46] Clagg S, Paterno MV, Hewett TE, Schmitt LC. Performance on the modified star excursion balance test at the time of return to sport following anterior cruciate ligament reconstruction. J Orthop Sports Phys Ther. 2015;45: 444-52. 
[47] Ageberg E, Forssblad M, Herbertsson P, Roos EM. Sex differences in patientreported outcomes after anterior cruciate ligament reconstruction: data from the Swedish knee ligament register. Am J Sports Med. 2010;38: 1334-42. 